\title{
The coroner's necropsy in sudden death: an under-used source of epidemiological information
}

\author{
J P O'Sullivan
}

\begin{abstract}
Aims-To determine the number of unsuspected disease processes found in a series of cases of sudden unexpected death occurring outside hospital and to enumerate how many of these were not recorded on the death certificate.

Methods-In a series of 1000 routine coroners' necropsies for sudden unexpected death, major findings that had not been known about in life were recorded. Macroscopic findings were confirmed histologically as appropriate. The deaths occurred either outside hospital or in the Accident and Emergency department before the patient could be examined. Cot deaths and decomposed bodies were excluded.

Results-There were 575 major findings in $532(53.2 \%)$ subjects that had been clinically silent in life. Of these 575 findings, $277(48.2 \%)$ were not the cause of death and so did not appear on the death certificate. Eighty per cent of the major alimentary system findings and all of the genitourinary findings were of this type. In addition, however, $30 \%$ of the major cardiovascular and $34 \%$ of the major respiratory findings were not recorded on the death certificate for this reason.

Conclusions-A large amount of important epidemiological data is being lost in the operation of the coronial system. Some of this information is irrecoverable as the function of the death certificate is to provide a cause of death only. In addition, information may be being lost because the necropsy is not being performed adequately and is not subject to audit. (F Clin Pathol 1996;49:737-740)
\end{abstract}

Keywords: necropsy, epidemiology, death certification, sudden death.

More than $90 \%$ of postmortem examinations in England and Wales are performed for HM Coroner ${ }^{1}$ and the majority of these are on cases of sudden death occurring outside hospital. These necropsies could constitute a valuable source of epidemiological information but the data are potentially flawed for two reasons: first, the death certificate only includes causes of death, thus excluding major conditions found at necropsy but not considered to have contributed to the death; and, second, at present there is no check on the quality of the performance of coroners' necropsies. The present study was undertaken to quantify the major findings present at necropsy that were clinically unsuspected in life in a series of necropsies for sudden death outside hospital. This was partly to see how common such findings were and also to discover how many of these would not appear on the death certificate because they were not considered to be causally related to the death.

\section{Methods}

The series comprises 1000 consecutive personally performed necropsies on cases of sudden unexpected death between October 1988 and February 1995. The subjects were either dead on arrival at hospital or died in the Accident and Emergency department before they could be examined. The cases were referred to the coroner either because the deceased person had not been seen by a doctor before death or, if they had been receiving medical treatment, death occurred unexpectedly and the attending doctor felt unable to give a cause of death. Cases of sudden infant death syndrome were excluded, as were cases where the body was too decomposed for adequate examination.

The necropsies were performed in a standard manner and special techniques such as radiology were not used. The naked eye findings were supplemented by histological examination where appropriate, but organs such as prostate and thyroid were not routinely sampled in a search for occult neoplasms.

The history was obtained by the coroner's officer from the family and, generally, also from the family doctor. A finding was included as unsuspected if there were no features in the history that would have led the deceased to seek medical attention for it. Coronary artery atheroma and myocardial fibrosis were not considered to be unsuspected findings in this sense in a predominantly elderly British population. However 'silent' myocardial infarction, verified histologically, was taken to be an unsuspected finding as the patient would probably have been referred for hospital admission had the diagnosis been made in life.

Findings were classified as major if their discovery in life would have led to investigation and possible treatment in hospital. These were not always life threatening conditions-for example, renal calculi, nor did they have to be the cause of death-for example, asymptomatic meningiomas.

Results

The numbers of deaths due to natural causes, accidental deaths and suicides are given in table 1 together with the age and sex distributions. There were $\mathbf{5 7 5}$ major findings in $\mathbf{5 3 2}$ 
Table 1 Numbers of deaths due to natural causes, accidental deaths and suicides, together with the age and sex distributions

\begin{tabular}{|c|c|c|c|c|c|}
\hline \multirow[t]{2}{*}{ Type of death } & \multirow[t]{2}{*}{ Total } & \multicolumn{2}{|l|}{ Males } & \multicolumn{2}{|l|}{ Females } \\
\hline & & Number & $\begin{array}{l}\text { Mean age (range) } \\
\text { in years }\end{array}$ & Number & $\begin{array}{l}\text { Mean age (range) } \\
\text { in years }\end{array}$ \\
\hline Natural & 873 & 499 & $72.2(26-94)$ & 374 & $76.8(21-100)$ \\
\hline Accidental & 66 & 49 & $41.9(13-82)$ & 17 & $53.8(2-95)$ \\
\hline Suicide & 61 & 51 & $42.6(19-85)$ & 10 & $52.2(22-78)$ \\
\hline
\end{tabular}

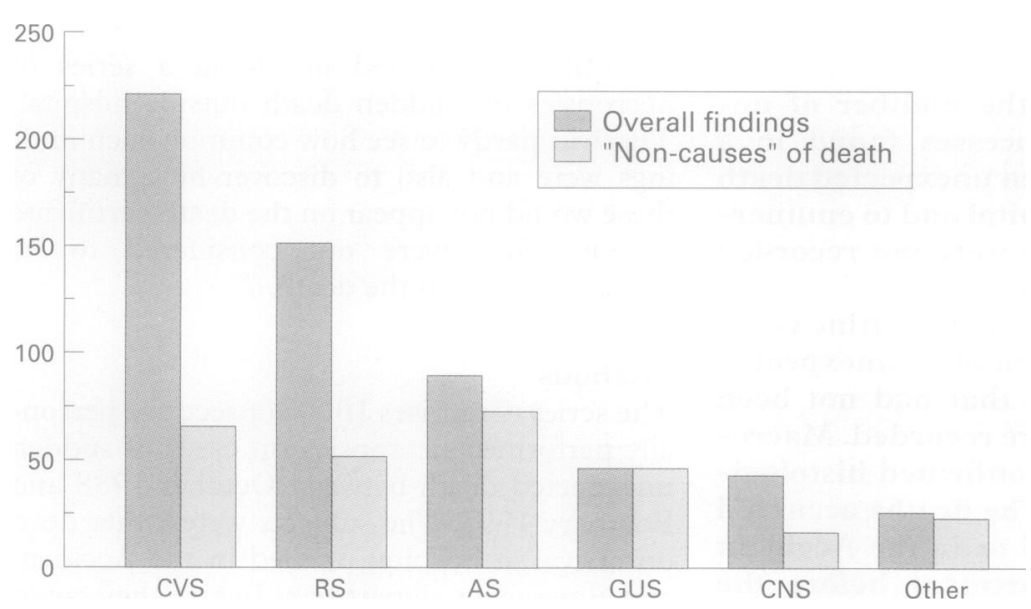

Figure 1 Comparison of the number of "non-causes" of death with the total number of major findings in each system. and Wales. Of these, 125060 (22.5\%) underwent a coroner's postmortem examination. This represents $93 \%$ of all necropsies performed on those aged 28 days or over and is a vast potential source of high quality epidemiological information.

This study shows that approximately one in every two coroners' postmortem examinations for sudden death in a predominantly elderly, semi-rural population will reveal one or more major disease processes that were unsuspected in life. Conditions where the diagnoses were known or suspected were excluded, such as bronchopneumonia in a person being treated for a chest infection, as were diseases such as cirrhosis in a known heavy drinker, where the diagnosis was not unlikely, even with no clinical features in life. Unsuspected carcinoma of the bronchus, however, was included as a smoking history was not taken routinely.

The postmortem examinations in this series were carefully, but not obsessively, performed. Attention has been drawn to the disparity between the history and the findings in forensic necropsies ${ }^{2}$ and there have been series on causes of natural death ${ }^{3}$ and the incidence of liver lesions ${ }^{4}$ in a necropsy population within the coronial system, but the present study is the first to enumerate the large number of major findings that were unsuspected in life in a series of coroners' necropsies for sudden death.

As fig 1 shows, a proportion of valuable information is inaccessible to the statistical services as it does not appear on the death certificate. The death certificate requests information only on the "disease or condition directly leading to death, morbid conditions, if any, giving rise to the above cause, .... and other significant conditions contributing to the death, but not related to the disease or condition causing it" [My italics]. Thus, major conditions may not be recorded. Two examples from the series illustrate this. An 82 year old woman died of ischaemic heart disease. She was found to have a meningioma and an intact aortic aneurysm, neither of which was known abou in life. As neither was a direct cause of death, they did not appear on the death certificate. A renal staghorn calculus was found incidentally in a 78 year old man who died of cardiac tamponade as a result of a silent myocardial infarction. This was clearly not related to the death

In $1992^{1}$ there were 555358 deaths from all causes in those aged 28 days or over in England

Table 2 Major unsuspected findings

\begin{tabular}{|c|c|c|c|}
\hline Anatomical site & Major findings & $n$ & Three commonest findings \\
\hline Cardiovascular system & 221 & 199 & $\begin{array}{l}\text { Myocardial infarction }(n=60) \\
\text { Intact aortic aneurysm }(n=52) \\
\text { Ruptured atheromatous aortic aneurysm }(n=40)\end{array}$ \\
\hline Respiratory system & 151 & 140 & $\begin{array}{l}\text { Bronchopneumonia }(n=46) \\
\text { Pulmonary embolism }(n=42) \\
\text { Bronchial carcinoma }(n=17)\end{array}$ \\
\hline Alimentary system & 90 & 84 & $\begin{array}{l}\text { Benign tumours and hamartomas }(n=33) \\
\text { Malignant tumours }(n=20) \\
\text { Active duodenal ulceration }(n=13)\end{array}$ \\
\hline Genitourinary system & 46 & 44 & $\begin{array}{l}\text { Renal calculus }(n=11) \\
\text { Renal cell carcinoma }(n=10) \\
\text { Bladder calculus }(n=8)\end{array}$ \\
\hline Central nervous system & 43 & 41 & $\begin{array}{l}\text { Recent infarction or haemorrhage }(n=17) \\
\text { Subarachnoid haemorrhage }(n=8) \\
\text { Old cerebral or cerebellar infarction }(n=8)\end{array}$ \\
\hline $\begin{array}{l}\text { Other } \\
\text { Total }\end{array}$ & 24 & 24 & \\
\hline
\end{tabular}


Table 3 Major unsuspected findings unrelated to the cause of death

\begin{tabular}{llll}
\hline Anatomical site & Major findings & $n$ & Major unsuspected findings \\
\hline Cardiovascular system & 67 & 59 & Intact aortic aneurysm $(\mathrm{n}=52)$ \\
Respiratory system & 52 & 52 & Carcinoma of lung $(\mathrm{n}=10)$ \\
Alimentary system & 72 & 67 & Carcinoma/carcinoid $(\mathrm{n}=15)$ \\
Genitourinary system & 46 & 44 & Renal calculus $(\mathrm{n}=11)$ \\
Central nervous system & 17 & 15 & Old cerebral/cerebellar infarction $(\mathrm{n}=8)$ \\
Other & 23 & 23 & \\
Total & 277 & 260 & \\
\hline
\end{tabular}

$\mathrm{n}=$ number of subjects.
Even when they are performed by specialist histopathologists, there is reason to believe that postmortem examinations may not always be conducted to the highest professional standard. This is even more likely to be the case in coroners' necropsies performed on cases of sudden death outside hospital. It is almost unknown for there to be a clinician in attendance at the time of the necropsy, and so there is little incentive for careful dissection and display of the organs by the pathologist. The Royal College of Pathologists ${ }^{10}$ has recommended that for a postmortem to be considered satisfactory, the brain must be examined. The fact that such a statement is considered necessary suggests that some histopathologists do not routinely examine the brain. This is also supported by the observation in one of the confidential enquiries ${ }^{7}$ that in $8 \%$ of cases there was no evidence that the skull and the brain had been examined. Yet there was a major central nervous system finding in just under one postmortem examination in every 20 for sudden death in the present series.

Thus, it is suggested that there is a loss of information within the coronial system for two reasons: first, the structure of the death certificate, which permits only the recording of causes of death; and, second, the lack of audit of the performance and reporting of necropsies. The findings from this series of 1000 cases of sudden death indicate that this loss of information is considerable.

The problem of the loss of data on disease processes, because they are not causative in the death, has been commented on ${ }^{11}$ and the use of a supplementary check list has been suggested. This study is the first to show the amount of such statistically inaccessible information. This information would be of value in measuring the state of the nation's health, in deciding on the provision of health resources and in assessing screening programmes, particularly in the elderly. A possible solution is a central database, similar to the one reported from Japan, ${ }^{12}$ where a copy of all necropsy reports could be lodged and where all the major findings would be coded and made available to interested parties. This could be combined with audit of the reports and it may be that this is an area where the Royal College of Pathologists and the Office of Population, Censuses and Surveys could usefully collaborate. There would seem to be a clear case for audit of necropsy performance, perhaps by a programme of random visits organised by the Royal College of Pathologists. In addition, there should be audit of the necropsy reports, to ensure that they contained a minimum data set-for example, the organ weights, as suggested by a Royal College of Pathologists' report. ${ }^{10}$

It is widely agreed that the postmortem examination can provide the best information on the disease processes present at death. Hospital postmortem examination rates are in universal decline ${ }^{13}$ and more than $90 \%$ of necropsies in England and Wales are performed within the coronial system. At current rates, these cost in excess of $£ 8$ million annually in the fees paid. Two major themes in discussions tologists. As these necropsies command a fee, it cult to see what motive other than cial can lie behind such inappropriately qualified persons performing these examinations. This practice cannot be conducive to high standards of performance and reporting. 
on the economics of health care in the developed world are efficiency-that is, spending money in a cost-effective way, and the rationing of limited resources. This study shows that the country could get much better value for its money in this area if the death certificate were modified to allow more information to be recorded and if there was audit of coroners' necropsies.

I thank Mr M Calvert-Lee, HM Coroner for West Sussex, for his helpful comments and suggestions on the manuscript.

1 Office of Population Censuses and Surveys. Mortality statistics general 1992. (Series DH1 no. 27.) London: Office of Population Censuses and Surveys, 1992

2 Hirsch CS. Forensic pathology and the autopsy. Arch Pathol Lab Med 1984;108:484-9.

3 Thomas AC, Knapman PA, Krikler DM, Davies MJ. Community study of the causes of "natural" sudden death BMF 1988;297:1453-6.
4 Berry CL. Liver lesions in an autopsy population. Hum Toxicol 1987;6:209-14.

5 Department of Health. Report on Confidential Enquiries into Maternal Deaths in the United Kingdom 1985-87. London: HMSO, 1991:133.

6 Department of Health. Confidential Enquiry into Stillbirths and Deaths in Infancy. Report 1 January - 31 December 1993. London: HMSO, 1995;Part I:53.

7 The Report of the National Confidential Enquiry into Perioperative Deaths 1991/1992. London: NCEPOD, 1993.

8 Royal College of Pathologists. Coroner's autopsies. In: Bulletin of the Royal College of Pathologists. London: Roya College of Pathologists, 1988;(62):15.

9 Kavanagh G. Coroners'rules and statutes. London: Sweet and Maxwell, 1985:40.

10 Royal College of Pathologists. Guidelines for post mortem reports. London: Royal College of Pathologists, 1993.

11 Ashworth TG. Inadequacy of death certification: proposal for change. 7 Clin Pathol 1991;44:265-8.

12 Baba K, Aizawa S. Nationwide autopsy registration over 30 years. In: Riboli E, Delendi M, eds. Autopsy in epidemiology and medical research. Lyon: IARC, 1991.

13 Flynn FV. A perspective of pathology across the Englishspeaking world. ACP News 1990;Autumn:4-5. 